\title{
Aneurysmal Subarachnoid Hemorrhage Guidelines from the Canadian Neurosurgical Society
}

\author{
J.M. Findlay and a Canadian Neurosurgical Society practice \\ guidelines review group*
}

\begin{abstract}
Published medical evidence pertaining to the management of aneurysmal subarachnoid hemorrhage (SAH) was critically reviewed in order to prepare practice guidelines for this condition. SAH should be considered as a possible cause of all sudden and/or unusual headaches, and every attempt should be made to recognize mild SAHs, as they are still frequently misdiagnosed. The first test for SAH is computed tomography (CT), followed by lumbar puncture when the CT is negative for intracranial bleeding (the case in only several per cent of patients within 24 hours of aneurysm bleeding). Urgent cerebral angiography is necessary to detect the underlying cerebral aneurysm. The advantage of rapid diagnosis of SAH followed by early aneurysm repair is minimizing the risk of catastrophic aneurysm rebleeding. Early surgery for aneurysm repair is often possible and is recommended, unless the aneurysm location or size renders it technically difficult to expose in clot-laden subarachnoid cisterns beneath an acutely swollen brain. Aneurysm ablation is optimally accomplished with open microsurgery and clipping of the aneurysm neck, although other options include proximal parent artery occlusion, "trapping" of the aneurysmal segment of the artery, and embolization of thrombogenic materials (e.g., platinum "microcoils") directly into the aneurysm dome using endovascular techniques. Neurological outcome following SAH is also optimized through the prevention of secondary SAH complications, and further management specific for ruptured cerebral aneurysms can include anticonvulsants, neuroprotectants, and various agents and techniques to prevent or reverse delayed-onset cerebral vasospasm. All patients with aneurysmal SAH should be treated with the calcium antagonist nimodipine, and in certain circumstances patients should receive anticonvulsants. Induced arterial hypertension, hypervolemia and in some instances percutaneous balloon angioplasty are recommended to reverse vasospasm causing symptomatic cerebral ischemia prior to cerebral infarction.
\end{abstract}

RÉSUMÉ: Traitement actuel de l'hémorragie sous-arachnoïdienne anévrismale Lignes de conduite de la Société Canadienne de Neurologie. Les données médicales publiées concernant le traitement de l'hémorragie sous-arachnoïdienne anévrismale (HSA) ont été revisées de façon critique afin de préparer des lignes de conduite pratiques pour le traitement de cette affection. L'HSA devrait être considérée comme une cause possible de toutes les céphalées subites et/ou inusitées et tous les efforts devraient être faits pour reconnaître les HSA légères parce qu'elles sont encore fréquemment mal diagnostiquées. Le premier test pour l'HSA est la tomodensitométrie (CT), suivie de la ponction lombaire quand le CT est négatif pour un saignement intracrânien (ce qui est le cas chez un faible pourcentage des patients dans les 24 heures d'un saignement provenant d'un anévrisme). L'angiographie cérébrale faite en urgence est nécessaire pour détecter l'anévrisme cérébral sous-jacent. L'avantage d'un diagnostic rapide de l'HSA suivi d'une réfection précoce est de minimiser le risque de resaignement catastrophique de l'anévrisme. La chirurgie précoce est souvent possible et est recommandée, à moins que le site de l'anévrisme ou sa taille le rende difficile d'accès dans les confluents sous-arachnoïdiens chargés de caillots, sous un cerveau oedématié de façon aiguë. L'exérèse de l'anévrisme est effectué idéalement par microchirurgie ouverte et ligature du collet de l'anévrisme, bien qu'il existe d'autres options comme l'occlusion proximale de l'artère qui nourrit l'anévrisme, le "trapping" du segment artériel anévrismal, l'embolisation d'une substance thrombogénique (microserpentins de platine par exemple) directement dans le dôme de l'anévrisme au moyen de techniques endovasculaires. L'issue neurologique suite à l'HSA est également optimisée par la prévention de complications secondaires de l'HSA et leur traitement spécifique inclut les anticonvulsivants, les neuroprotecteurs et d'autres agents et techniques pour prévenir ou faire régresser le vasospasme cérébral tardif. Tous les patients qui ont une HSA devraient être traités avec la nimodipine, un antagoniste du calcium, et dans certaines circonstances, les patients devraient recevoir des anticonvulsivants. L'hypertension artérielle induite, l'hypervolémie et dans certains cas l'angioplastie percutanée, sont recommandées pour maîtriser le vasospasme causant l'ischémie cérébrale symptomatique avant que ne survienne l'infarctus cérébral.

Can. J. Neurol. Sci. 1997; 24:161-170

Subarachnoid hemorrhage (SAH) from a ruptured cerebral aneurysm is a common and often devastating medical emergency. The annual incidence of SAH in North America is approximately 10 cases per 100,000 persons, ${ }^{1}$ and it has been estimated that up
RECEIVED SEPTEMBER 24, 1996. ACCEPTED IN FINAL FORM DECEMBER 7, 1996. *H.D. Fewer, W.O. Gittens, R.W. Griebel, R.O. Holness, H. Hugenholtz, G.J. Redekop, D.E. Steinke and M.C. Wallace.

Reprint requests to: J. Max Findlay, Division of Neurosurgery, University of Alberta, 2D1.02 WMHSC, 8440 - 112 Street, Edmonton, Alberta, Canada T6G 2B7 
to one-half of those suffering aneurysm rupture will either die or be seriously disabled as a result. ${ }^{1-3}$ Although poor outcome is often primarily due to direct effects of the initial hemorrhage, timely and appropriate management of these patients will prevent secondary complications and additional neurological injury.

The following practice guidelines were prepared by Canadian Neurosurgical Society to update the Canadian neuroscience community on current management recommendations for aneurysmal SAH. The levels of evidence established by the Canadian Task Force on the Periodic Health Examinations were applied. ${ }^{4}$ These recommendations are based upon a review of the pertinent literature to date, but since most studies in this area are nonrandomized trials or case series (levels II and III evidence, Table 1), all recommendations required consensus from a panel of experts. It should be emphasized that the following management recommendations have been formulated as guidelines only, to complement rather than replace clinical judgment, since individual patient and clinical circumstances sometimes require variation from the treatments strategies set forth below. Wherever appropriate, these guidelines were compared with similar guidelines, published in 1994, from a special writing group of the American Heart Association, ${ }^{5,6}$ to ensure no serious discrepancies arose.

\section{Table 1:}

\section{Canadian Task Force classification of study designs}

I Evidence obtained from at least one properly designed randomized controlled trial.

II-1 Evidence obtained from well-designed controlled trials without randomization.

II-2 Evidence obtained from well-designed cohort or case-control analytic studies, preferably from more than one centre or research group.

II-3 Evidence obtained from comparisons between times or places with or without intervention; dramatic results in uncontrolled experiments (such as the results of treatment with penicillin in the 1940s) could also be included in this category.

III Opinions of respected authorities, based on clinical experience, descriptive studies, or reports of an expert panel.

\section{Categories for strength of each recommendation}

\begin{tabular}{cl}
\hline Category & \multicolumn{1}{c}{ Definition } \\
\hline A & Good evidence to support a recommendation for use \\
B & Moderate evidence to support a recommendation for use \\
C & Poor evidence to support a recommendation against use \\
D & Moderate evidence to support a recommendation against use \\
E & Good evidence to support a recommendation against use
\end{tabular}

\section{Clinical grading and diagnosis of SAH}

The characteristic symptoms of SAH are sudden, worst-ever headache, emesis, and the development of a painful, stiff neck (meningismus) over several hours. Generally speaking, the smaller the SAH, the fewer the symptoms and signs. A SAH causing sudden headache that then steadily abates without an alteration in consciousness usually corresponds to mild bleeding. In reference to the more severe rebleeding from an aneurysm that often follows if the patient remains untreated, mild hemorrhages are sometimes referred to as a "warning" or "sentinel" leaks.

The variable severity of aneurysm bleeding, and the corre- sponding range of conditions SAH patients present in, is expressed in SAH grading scales derived from a system originated by Botterell and Lougheed at The Toronto General Hospital in the 1950 s. $^{7}$ In current and commonly used SAH scales such as the modified Botterell and Lougheed scale, ${ }^{8}$ and the Hunt and Hess scale ${ }^{9}$ grade I represents mild to moderate headache; grade II, severe headache but alert; grade III, drowsy with otherwise minimal neurological deficit; grade IV, comatose; and grade $\mathrm{V}$, moribund with brainstem dysfunction (Table 2). The grading scale devised by the World Federation of Neurological Surgeons is often used in multicentre trials of subarachnoid hemorrhage $^{10}$ (Table 2). Additional scoring using the Glasgow Coma Scale is helpful in assessing grades IV and V patients. Any specific focal or lateralizing neurological deficits are also noted.

\section{Table 2: Subarachnoid Hemorrhage Grading Scales}

\section{Botterell-Lougheed}

Grade I: (minimal bleed) alert, no neurological deficit

Grade 11: (mild bleed) alert, minimal neurological deficit such as third nerve palsy, stiff neck.

Grade III: (moderate bleed) drowsy or confused, stiff neck, with or without neurological deficit.

Grade IV: (moderate or severe bleed) semi-coma, with or without neurological deficit.

Grade V: (severe bleed) coma and decerebrate movements.

\begin{tabular}{|c|c|c|c|}
\hline \multicolumn{4}{|c|}{ Hunt-Hess } \\
\hline Grade I: & \multicolumn{3}{|c|}{$\begin{array}{l}\text { Asymptomatic, or minimal headache and slight nuchal } \\
\text { rigidity }\end{array}$} \\
\hline Grade II: & \multicolumn{3}{|c|}{$\begin{array}{l}\text { Moderate to severe headache, nuchal rigidity, no neurolog } \\
\text { ical deficit other than cranial nerve palsy }\end{array}$} \\
\hline Grade III: & \multicolumn{3}{|c|}{ Drowsiness, confusion, or mild focal deficit } \\
\hline Grade IV: & \multicolumn{3}{|c|}{$\begin{array}{l}\text { Stupor, moderate to severe hemiparesis, possibly early } \\
\text { decerebrate rigidity and vegetative disturbances }\end{array}$} \\
\hline Grade V: & \multicolumn{3}{|c|}{ Deep coma, decerebrate rigidity, moribund appearance } \\
\hline & \multicolumn{3}{|c|}{ World Federation of Neurological Surgeons } \\
\hline & $\begin{array}{l}\text { MFNS } \\
\text { Grade }\end{array}$ & $\begin{array}{l}\text { GCS* } \\
\text { Score }\end{array}$ & $\begin{array}{l}\text { Motor } \\
\text { Deficit }\end{array}$ \\
\hline & $\mathrm{I}$ & 15 & absent \\
\hline & II & $14-13$ & absent \\
\hline & III & $14-13$ & present \\
\hline & IV & $12-7$ & present or absent \\
\hline & $\mathrm{V}$ & $6-3$ & present or absent \\
\hline
\end{tabular}

Misdiagnosis of SAH continues to be a significant problem, often with serious consequences. Roughly $25 \%$ of patients admitted to neurosurgical units with SAH have suffered a prior hemorrhage that was not recognized when the patient first sought medical attention. ${ }^{11}$ Because repeat and more severe hemorrhaging commonly occurs in this group, these patients have a poorer overall prognosis ${ }^{12,13}$ than those without a history of prior bleeding. Therefore neurosurgeons must continue to emphasize to emergency and primary care physicians that $S A H$ must be considered when a headache is sudden in onset, unusual to the patient in terms of its severity and nature, and painful enough to bring it to medical attention. The spontaneous development of a third cranial nerve palsy (with pupillary involvement) may indicate acute expansion or rupture of usually a carotid artery aneurysm adjacent to the oculomotor nerve. 
The investigation of choice to diagnose SAH is unenhanced (noncontrast) computed tomography (CT) of the head ${ }^{14}$ (Table 3) (category A recommendation). When performed within a day of aneurysm rupture, CT reveals high-density (white) blood clot in basal subarachnoid cisterns in roughly $95 \%$ of patients. ${ }^{15,16}$ Patients presenting with a depressed level of consciousness due to a significant SAH uniformly have CT scans positive for blood. As SAH is a medical emergency, it is recommended that patients with suspected acute SAH presenting at a facility without a CT scanner be referred to the nearest institution with a scanner, and preferably also with neurosurgical coverage, as soon as possible ${ }^{17}$ (category A). In addition to detecting the presence of SAH, CT scanning also provides an estimate of the origin and extent of the hemorrhage, and it allows recognition of associated intracerebral hemorrhage (ICH), intraventricular hemorrhage (IVH), and hydrocephalus. Rarely, aneurysm rupture will result in the formation of an acute subdural hemorrhage (approximately $2 \%$ of patients), due to dissection of blood through the arachnoid membrane into the subdural space. ${ }^{18}$ Hence, in the setting of the spontaneous appearance of a subdural hematoma and the coincident presence of subarachnoid blood on CT scan, an underlying ruptured aneurysm should be suspected.

\section{Table 3:}

\begin{tabular}{|c|c|}
\hline \multicolumn{2}{|c|}{ Diagnosis of Subarachnoid Hemorrhage } \\
\hline Investigation & Comment/Recommendation category \\
\hline computed tomography (CT) & $\begin{array}{l}\text { investigation of choice, positive in over } \\
95 \% \text { of patients within } 24 \text { hours of rup- } \\
\text { ture (cat. A) }\end{array}$ \\
\hline lumbar puncture & $\begin{array}{l}\text { all patients with suspected SAH and } \\
\text { CTs negative for hemorrhage (cat. A) }\end{array}$ \\
\hline cerebral angiography & $\begin{array}{l}\text { as soon as can be performed (cat. B) } \\
\text { CT-angiography in emergency situa- } \\
\text { tions when available (cat. B) }\end{array}$ \\
\hline
\end{tabular}

While CT scanning is strongly recommended first in all patients with suspected SAH, those presenting with acute but mild (grade I) SAH, and those patients investigated several days after SAH may have a normal CT scan. In all cases where SAH is suspected but the CT scan is interpreted as normal by a trained observer, a lumbar puncture should be performed (category A recommendation).

Physicians undertaking a lumbar puncture to diagnose SAH should be aware that this procedure has been reported to precipitate aneurysm rebleeding, although this occurrence is rare. ${ }^{19} \mathrm{It}$ is also recommended that they be familiar not only with the technique of lumbar puncture, but also with the methods used to distinguish a pre-existing "true" SAH from a traumatic SAH resulting from the lumbar puncture itself. ${ }^{14} \mathrm{~A}$ constant level of thousands of red blood cells per $\mathrm{mm}^{3}$ of cerebrospinal fluid (CSF) in sequential tubes of collected CSF is suggestive of true SAH, particularly when the CSF supernatant remains xanthochromic after centrifugation. Centrifugation causes sedimentation of intact cellular elements from the CSF, so that yellow pigmentation of the resultant CSF is due to free hemoglobin in solution. This indicates the presence of red blood cells in the CSF for at least several hours prior to the lumbar puncture by which time spontaneous erythrocyte lysis occurred. Clear CSF following centrifugation indicates that only intact erthrocytes were staining the CSF confirming a traumatic tap.

Spectrophotometry is superior to the naked eye in detecting CSF xanthochromia, ${ }^{20}$ but this investigation is not available in all hospital emergency laboratories. It should be emphasized that no type of CSF analysis is fail-safe in making the distinction between true and traumatic $\mathrm{SAH}$, and that if any doubt remains in the clinician's mind, a neurosurgical consultation is recommended. In some such instances, direct imaging of the cerebral arteries is the only certain way to exclude a cerebral aneurysm. On the other hand, if both the CT and CSF analysis are normal within several days of suspected aneurysm rupture, then SAH can be confidently ruled out, and cerebral artery imaging is not indicated ${ }^{14}$ (category D).

At the present time selective, catheter cerebral angiography remains the current standard for diagnosing cerebral aneurysms causing SAH. Although there are no data in the literature that address this issue directly, cerebral angiography is recommended as soon as it can be safely performed in all patients with spontaneous SAH who are not moribund (category B recommendation). Those patients with unilateral uncal herniation due to a parenchymal hematoma and where the herniation syndrome has been stopped or temporarily reversed by medical treatment to lower intracranial pressure (hyperventilation and mannitol administration) should, whenever possible, undergo immediate angiography (category $\mathrm{B}$ recommendation). Most neuroradiologists and neurosurgeons prefer to defer angiography until the following morning if a SAH patient presents in the late evening or night and is neurologically stable. If the patient is in a stable medical and neurological condition, it is considered by many safer to wait until complete, experienced and fresh angiography and surgical teams are available in the morning (category $\mathrm{C}$ recommendation).

A promising new diagnostic technique is computed tomographic angiography (CTA) ${ }^{21-23} \mathrm{~A}$ helical CT scanner is used to scan the patient's head following the rapid, power injection of a contrast bolus, and the axial images obtained are then reconstructed to provide three-dimensional vascular anatomical information. The technique is relatively less invasive than catheter angiography, fast, and can provide a multitangential view of the arteries and aneurysm complex, including its relationship to adjacent bony structures. Adjacent cisternal blood does not interfere with the images, although as with conventional angiography only the part of aneurysms filling with contrast agent will be opacified and demonstrated. While this technique is still under development, it appears likely that its sensitivity and specificity compared to the gold-standard catheter angiography will be sufficient to replace the latter at least in emergency situations.

\section{Immediate treatment measures}

All aneurysm patients must be protected from acute rebleeding, which is most common in the minutes and hours following initial aneurysm rupture $(4.1 \%$ in the first 24 hours of the Cooperative Aneurysm Study). ${ }^{24}$ Acute arterial hypertension in response to a painful and frightening SAH plays a role in early rebleeding, and it is recommended that patients with suspected SAH be treated with adequate analgesia prior to investigations (category A). It is also recommended that in patients in "good" condition (grades I-III) without evidence of raised intracranial 
pressure (ICP) either clinically or on CT, persistent hypertension be lowered pharmacologically with intravenous labetolol or hydralazine (Table 4) (category A). Sublingual or oral antihypertensives are less reliable alternatives, and are not first choice in this setting (category D).

\section{Table 4:}

Pharmacological Management of SAH

\begin{tabular}{ll}
\hline Agent(s) & Comment/Recommendation category \\
\hline antihypertensives & $\begin{array}{l}\text { intravenous agents (i.e., labetolol, } \\
\text { hydralazine) for acute hypertension fol- } \\
\text { lowing SAH unresponsive to analgesia } \\
\text { in awake patients (unprotected } \\
\text { aneurysm) (cat. A) } \\
\text { patients with documented seizure, corti- } \\
\text { cal hemorrhage or infarction, or in } \\
\text { coma (cat. B) } \\
\text { not recommended (cat. E) } \\
\text { no evidence to support their use } \\
\text { recommended for all patients until time } \\
\text { of discharge (patients in good condition } \\
\text { antifibrinolytic agents } \\
\text { corticosteroids } \\
\text { nimodipine }\end{array}$ \\
& 21 days from SAH (cat. A)
\end{tabular}

Grade IV (semi-comatose) SAH patients have a more than doubled acute rebleeding rate and a higher incidence of severe arterial hypertension. Rebleeding within 24 hours of admission has also been found to correlate with rebleeding prior to admission, high systolic blood pressure, intracerebral or intraventricular hematoma, and those who undergo angiography within 6 hours of the last $\mathrm{SAH} .{ }^{25}$ These patients frequently have elevated ICP, so that excessive lowering of blood pressure may result in inadequate cerebral perfusion pressure (CPP) and cerebral infarction. In semicomatose or comatose SAH patients, pharmacological lowering of arterial hypertension is not recommended until neurosurgical consultation is obtained and the CPP is monitored (category D). These patients usually require intubation during or following the initial assessment, and prior to angiography. Early ventriculostomy enables treatment of raised ICP, which is sometimes accompanied by clinical improvement, and allows calculation of the CPP for more appropriate blood pressure control. ${ }^{26}$

It is recommended that Grade $\mathrm{V}$ (moribund) SAH patients who are either elderly (i.e., > 70 years old), or have obvious vital, deep brain destruction on CT scan receive only compassionate care, or that they are provided only temporary cardiorespiratory support if brain death is imminent and organ donation is being considered (category $\mathrm{C}$ ). Younger patients who have failing brainstem function in the absence of clear vital brain destruction on CT often undergo ventricular drainage, and further aneurysm treatment is undertaken if their clinical condition improves, for example as demonstrated by the recovery of a localizing motor response. Intractably elevated ICP or poor angiographic filling of the cerebral vasculature on angiography are generally regarded as contraindications to surgery ${ }^{26}$ (category $\mathrm{B}$ recommendation, grade III evidence). The early management of poor-grade patients with SAH is problematic, however. $A$ recent series of grades IV and $V$ patients treated uniformly with early surgery and aggressive postoperative measures was retrospectively reviewed to determine management results and what factors predicted outcome. ${ }^{27}$ As has been the case in previous studies it was found that older age, poorer neurological status, greater amounts of intracranial bleeding and hypodense changes in cerebral parenchyma correlated significantly with worse outcome. However a multivariate analysis of these factors used in a preoperative model of outcome prediction applied to this same patient population correctly predicted favourable outcome (capable of independent life and all self-care) in only approximately $70 \%$ of patients. Thus, $30 \%$ of patients who went on to make a satisfactory recovery could not be accurately identified using standard poor-prognosis criteria, including age and Glasgow Coma Score (level II-2 evidence). While surgical results in poor-grade patients, compared to those in good-grade patients are unavoidably much poorer, it is possible that the best overall management results for poor-grade patients will be obtained following aggressive surgery and treatment. On the basis of currently available data, it is difficult to offer definitive recommendations regarding the care of poor-grade SAH patients.

Patients whose brainstem dysfunction is due to uncal herniation from a spontaneous, large cortical or subcortical blood clot that by its location is felt likely to be aneurysmal in origin should be treated urgently with intubation, hyperventilation and intravenous mannitol administration $(1 \mathrm{~g} / \mathrm{kg})$. If herniation can be temporarily reversed with these measures, an angiogram is recommended prior to craniotomy, although under these circumstances an aneurysm can sometimes be identified prior to surgery by rapid sequence axial $\mathrm{CT}$ scanning following a bolus intravenous administration of contrast agent, ${ }^{28}$ or CTA which was discussed previously. ${ }^{21-23}$

In the initial management phase of $\mathrm{SAH}$, pharmacological treatment is directed at pain, blood pressure and ICP control, as discussed above. There is no proven role for corticosteroids in the treatment of SAH.

\section{Aneurysm repair}

\section{Timing of surgery:}

The timing of aneurysm surgery has been the subject of considerable neurosurgical debate over the years. ${ }^{29}$ Following rebleeding there is an immediate mortality in roughly one-third of good grade patients and one-half of poor grade patients. ${ }^{30}$ The advantages of early surgery and aneurysm obliteration, in addition to eliminating the risk of rebleeding, include the possibility of removing subarachnoid blood and thereby reducing the risk of vasospasm, ${ }^{31,32}$ as well as allowing more aggressive treatment of symptomatic vasospasm with induced hypertension. Early surgery also avoids to some extent the complications of inactivity forced upon patients awaiting delayed surgery and may contribute to a shorter hospitalization. The disadvantage of early surgery is the possibility of a more swollen brain that, together with clot-laden subarachnoid cisterns, makes exposure of the aneurysm more difficult and the risk of intraoperative complications greater, although this latter point has recently been disputed in a single-institution, retrospective cohort study. ${ }^{33}$ As well, there is a concern that early surgery might, by preventing fatal rehemorrhages, preserve the life of patients destined to remain in poor neurological condition, thereby decreasing mortality at the expense of increased morbidity. 
The International Cooperative Study on Timing of Aneurysm Surgery was a prospective, nonrandomized study that examined the outcome of 3521 patients with acutely ruptured aneurysms that were treated with surgical clipping at various time intervals following primary hemorrhage, according to the philosophy and preference of the treating surgeon (grade II-2 evidence). ${ }^{34,35}$ As expected, it was found that early surgery conferred significant protection from rebleeding, but there was no significant difference in overall outcome related to timing of surgery. The group of patients who had surgery planned for days 7 through 10 had the least favourable outcome and the highest mortality rate, although this trend was not significant. Following publication of this report, an analysis of just those patients treated in North American centres revealed that early-surgery patients in this subgroup had significantly improved rates of good recovery as compared with the delayed-surgery patients. ${ }^{36}$

A single prospective, randomized study on the timing of operation for ruptured supratentorial aneurysms examined 216 grades I-III patients (grade I evidence). ${ }^{37}$ Operation within 3 days of SAH was associated with a trend toward better overall results, and deaths due to rebleeding did not occur in the early group. As in the Cooperative Study, operation during an "intermediate" period, 4-7 days after $\mathrm{SAH}$, was associated with more unfavourable outcomes, and this difference was significant when this group was compared to the early surgery group.

A rigid policy of early versus late aneurysm surgery cannot be defended at this time. In general, it is recommended that patients with acute SAH undergo aneurysm repair as early as possible following rupture, especially if their clinical condition is clearly compatible with a satisfactory neurological outcome (clinical grades I-III and selected grade IV patients) (category B recommendation, grade II-1 evidence). One small randomized trial indicated that early clot evacuation and aneurysm clipping for patients with intracerebral hemorrhages may be particularly valuable in improving outcome ${ }^{38}$ (grade II-1 evidence). Emergent surgery for grade $\mathrm{V}$ patients with peripheral clots causing uncal herniation is sometimes warranted, as discussed previously ${ }^{28,39}$ (category B recommendation, grade III evidence).

It appears that the timing of aneurysm surgery alone is not a strong determinant of outcome following aneurysm rupture, and some circumstances might call for a more delayed intervention. It is recommended that patients harboring ruptured aneurysms that by virtue of their size, morphological complexity, or anatomical location, are considered difficult to access surgically, especially in the acute stage of SAH when the brain is intolerant of prolonged or severe retraction, should be treated by delayed operation or endovascular techniques (next section) (category B recommendation, grade III evidence). The decision that early surgery is excessively dangerous in any individual patient rests with the treating surgeon. It is recommended that surgery during the "vasospastic interval", days 4-10 following SAH, be undertaken with caution, owing to the possibility of aggravating latent cerebral ischemia (category B, grade II-2 evidence). Surgery during this interval is especially precarious in the presence of significant cerebral vasospasm determined either by angiography or by cerebral blood flow studies.

\section{Endovascular aneurysm treatment:}

Currently, endovascular aneurysm occlusion is most often undertaken with thrombogenic "microcoils" deposited into the aneurysm dome through an arterial catheter. ${ }^{40-49}$ Performed in the neuroradiology suite, general anaesthesia is sometimes required to obtain a motionless patient, necessary for accurate and safe catheter and coil placement. The Guglielmi detachable coil (GDC) (Target Therapeutics, Freemont, CA, USA) system, the only one currently approved for use in Canada, uses delicate platinum wires of several different calibers and variable lengths (when straightened) that form different sized coils. These soft coils easily straighten to fit through a microcatheter and then reform their helical shape once advanced past the tip of the microcatheter into the aneurysm dome. They are detached from their stainless steel delivery wire atraumatically with an electrolytic current (1 to $2 \mathrm{~mA}$ ) passed through the guidewire which erodes a noninsulated solder connection between the delivery wire and coil. The number of coils required to completely occlude an aneurysm depends on the aneurysm size.

Endovascular treatment of aneurysms with GDC coils requires a specially trained interventional neuroradiologist or neurosurgeon. A combined analysis of selected series provided by the manufacturer (and reporting the best results in the literature) suggests that in expert hands the complication rates for the two major risks of the procedure, hemorrhage and arterial occlusion, to be approximately $6 \%$ and $2 \%$, respectively. Failure to completely occlude the aneurysm is a more common problem, and is usually a result of a wide aneurysm neck (greater than approximately $4 \mathrm{~mm}$ in diameter) associated with a larger aneurysm, that prevents packing of the dome with coils. Dense coil packing, necessary for complete aneurysm obliteration, is not possible when a wide aneurysm orifice permits coil herniation into the parent artery. Among the various reported series of patients that have undergone GDC coiling, the percentage of incomplete occlusions depends on the number of patients with large aneurysms that were treated. For example, in a recently reported series of 33 basilar tip aneurysms where 17 were greater than $10 \mathrm{~mm}$ in diameter, only $7(21 \%)$ could be completely occluded by an experienced team of neurointerventionalists. ${ }^{50}$ In contrast, it has been reported that over $80 \%$ of small or "small-necked" aneurysms can be completely occluded with GDC coils in certain centres ${ }^{51-53}$ (level II-2 evidence). An aneurysm remnant following GDC treatment has a continued risk of bleeding as well as a recognized propensity to enlarge, owing to progressive compaction of the intraaneurysmal coils with pulsatile blood flow (the "water-hammer" effect). Bridging the entire neck area with a dense meshwork of coils appears to be a determining factor in preventing early aneurysm regrowth, although long-term follow-up of even completely occluded aneurysms is not yet available. It is quite possible that partial coil obliteration of the aneurysm dome reduces the rebleeding risk among those patients presenting with $\mathrm{SAH}$, and some anecdotal evidence would suggest this (level III evidence) ${ }^{50}$ This may then provide an opportunity for a more delayed intervention, including aneurysm neck-clipping. However, repair of aneurysms partly occluded with coils may be impeded by the presence of the non-compressible aneurysm coils and associated thrombus. ${ }^{54}$ Alternatively, a distal bypass conduit can be constructed followed by parent vessel occlusion.

The technique of aneurysm occlusion with GDC coils has opened up new opportunities in aneurysm treatment. In North America their use until now has been primarily in patients with 
aneurysms that are considered dangerous to clip, or in patients who either are considered unfit for surgery or refuse surgery. At present it is recommended that these continue to be the indications for this technique in those centres where it is available (category B, level III evidence). The use of this technique in broad-necked aneurysms where it is not possible to achieve a complete occlusion is controversial. It is unlikely that the results of this procedure in general practice will, at least initially, match the very good results reported from centres with already a broad experience with the technique. Unless future randomized trials demonstrate that the morbidity and mortality associated with endovascular occlusion are less than those associated with microsurgical clipping, and that aneurysm occlusion with coil embolization results in long-term cure over many years, surgical repair will remain the recommended first treatment choice for intracranial aneurysms (Table 5).

Table 5:

\begin{tabular}{ll}
\hline \multicolumn{2}{c}{ Surgical Methods of Aneurysm Repair } \\
\hline Method & Comment/Recommendation category \\
\hline clipping of aneurysm neck & treatment of choice (cat. A) \\
proximal parent artery ligation & sometimes indicated, effective (cat. A) \\
aneurysm "trapping" & sometimes indicated, effective (cat. A) \\
aneurysm "wrapping or & not recommended as sole treatment \\
"coating" & (cat. D)
\end{tabular}

\section{Proximal artery occlusion, antifibrinolytics, and aneurysm wrapping or coating:}

In selected patients with sufficient collateral flow, or in those patients where collateral flow has been provided with a surgically created bypass graft, ${ }^{55}$ occlusion of the parent artery proximal to a very large or giant aneurysm is an acceptable method of aneurysm treatment ${ }^{46,47,56}$ (level III evidence). Carotid ligation in the neck alone is not recommended, as the rebleeding rate may not be significantly lowered with this form of treatment ${ }^{57}$ (category $\mathrm{D}$, level III evidence). Endovascular detachable balloon, ${ }^{58}$ or more recently GDC occlusion ${ }^{49}$ and sacrifice of the immediately proximal parent artery is simpler and probably more efficacious than an open surgical occlusion in many instances. It is recommended that this form of treatment be followed by repeat angiography to ensure complete aneurysm thrombosis. Any continued aneurysm filling signals a persistent risk of rebleeding, and in such cases aneurysm trapping is recommended (category A, level III evidence).

The administration of antifibrinolytic agents, such as epsilon aminocaproic acid, to retard subarachnoid clot lysis and prevent aneurysm rebleeding until delayed surgery is undertaken, is not recommended. Nonrandomized and randomized trials have shown that while these agents reduce the rebleeding rate of acutely ruptured aneurysms, this benefit is offset by an increased rate of cerebral infarction, so that overall outcome is not improved $^{49-57}$ (category E recommendation, level I evidence). Similarly, coating or wrapping an aneurysm sac with a material to strengthen its wall or induce a strengthening fibrotic reaction does not completely protect from rebleeding and is not recommended for definitive aneurysm repair ${ }^{59,60}$ (category D, level III evidence).

\section{Perioperative care of SAH patients}

\section{Patient monitoring and the aneurysm team:}

It is recommended that all pre- and postoperative patients with impaired LOC be treated in an intensive care unit (ICU) or close-monitoring unit. ${ }^{61}$ While neurosurgeons play a central role in the management of SAH, "aneurysm teams" are being created in many centres to collaborate on individual patient treatment. Such teams are typically made up of neurosurgeons, neurologists, interventional neuroradiologists, intensive care physicians, and critical care nurses.

\section{Delayed surgery and the SAH "routine":}

Patients in whom definitive aneurysm clipping is being delayed should be managed in a quiet environment, with adequate analgesia and sedation, a bowel routine to reduce straining, and normotension with normo- to slight hypervolemia. Drug treatment during this period is the same as in the postoperative period described below.

\section{Monitoring and fluids:}

All SAH patients should be monitored with an indwelling arterial line initially, and a central venous line should be considered in any patient where volume status is a special concern, such as those patients with large volume SAHs at high risk of developing vasospasm. Pulmonary artery catheters are reserved for patients with cardiopulmonary instability or severe symptomatic vasospasm. Patients should receive isotonic fluids in sufficient amounts to maintain mild hypervolemia, and packed red blood cell infusions are given as necessary to avoid anemia ${ }^{62}$ (category B evidence, level III evidence). Hypovolemia and hypotonic intravenous fluids, which can aggravate cerebral ischemia and swelling, are carefully avoided ${ }^{63}$ During the acute phase of their illness patients should have complete blood counts, serum electrolytes, and arterial blood gases or oxygen saturation levels measured at least once daily.

\section{Pharmacological management of SAH:}

Risk factors that have been identified for seizures following aneurysm rupture include an MCA aneurysm location, parenchymal hemorrhage or infarction, a history of hypertension, persistent neurological deficit, and a young age ${ }^{64-68}$ (level II-2 evidence). Anticonvulsants are recommended at least for the short-term for any patient with a documented seizure in the acute phase of SAH, which was recorded in as many as onequarter of patients in one series (Table 4). ${ }^{69}$ Seizures must be distinguished clinically from episodes of rebleeding, which they can closely resemble. Although prophylactic anticonvulsants have not been proven effective following SAH in a randomized trial, they should be considered in patients with significant cortical damage or in coma (category B). Phenytoin is the recommended parenteral anticonvulsant under these circumstances, given as a $15 \mathrm{mg} / \mathrm{kg}$ loading dose followed by 3 to $5 \mathrm{mg} / \mathrm{kg} / \mathrm{day}$ in divided doses. If anticonvulsants are prescribed to aneurysm patients, then therapeutic serum levels of the drug should be ensured.

Corticosteroids have no clearly proven role following SAH, and are not recommended for routine use at this time (category $D$ ).

Six randomized controlled trials ${ }^{70-75}$ have shown that the calcium antagonist nimodipine has a modest but significant 
beneficial impact on clinical outcome following aneurysmal $\mathrm{SAH}$, although its mechanism of action is uncertain. Two metaanalyses have also indicated drug efficacy. ${ }^{76,77}$ The dosage of nimodipine is $60 \mathrm{mg}$ every 4 hours either orally or via a nasogastric tube. It is recommended for all SAH patients until either the time of discharge from hospital (with the patient in good condition and with no evidence of vasospasm) or for twenty-one days for patients hospitalized for this entire period of time with persistent neurological impairment (category A recommendation, level I evidence). It should be given with caution to patients with congestive heart failure or hepatic insufficiency due to the risk of aggravating these conditions.

\section{Vasospasm:}

Cerebral vasospasm is delayed-onset arterial narrowing following SAH, occurring usually between the fourth and fourteenth day following aneurysm rupture, but peaking in incidence and severity between the seventh and eleventh day. Cerebral ischemia due to vasospasm can lead to brain infarction, permanent disability and death. Vasospasm is an arterial response to subarachnoid blood clots, and patients at greatest risk for severe vasospasm are those with thick persistent clots evident on CT scan. $^{78}$

There is evidence that the intraoperative, intracisternal administration of the fibrinolytic agent recombinant tissue plasminogen activator (rt-PA) promotes clearance of subarachnoid clot, and significantly reduces severe angiographic vasospasm $^{79,80}$ (level I evidence). However, this treatment can induce severe aneurysm rebleeding if the aneurysm has been incompletely repaired prior to treatment, ${ }^{80}$ and it has not been proven to significantly improve outcome following $\mathrm{SAH}$ in a large series of patients.

When available, SAH patients can undergo daily transcranial Doppler (TCD) monitoring before and throughout the vasospastic interval. An increase in mean blood flow velocities over 150 $\mathrm{cm} / \mathrm{sec}$ as measured by TCD is suggestive of significant vasospasm $^{81-84}$ (level III evidence). Patients who exhibit early symptoms of cerebral ischemia and/or have a worrisome elevation of TCD velocities during the vasospastic interval should receive increased intravenous fluid administration, including colloid infusions, to achieve hypervolemia (category B recommendation, level III evidence). At this time the synthetic volume-expander hetastarch is not recommended for SAH patients, since it has been shown to induce coagulopathy through an unknown mechanism. ${ }^{85}$

Patients who develop symptomatic vasospasm should also be treated with hypervolemia and induced hypertension in an attempt to improve cerebral blood flow through the vasospastic arteries. Although recommended, the use of "triple-H therapy" (hypervolemia, hemodilution and hypertension) has never been confirmed efficacious in either a randomized or nonrandomized trial, and it is not known what component of the therapy, hypertension, hypervolemia, or hemodilution, is the most important in reversing cerebral ischemia. ${ }^{86-88}$ Significant hemodilution risks lowering oxygen delivery, and therefore it is recommended that the hematocrit be monitored and maintained above $35 \% .{ }^{89,90}$ Inotropes such as dopamine or dobutamine are used, and if the neurological deficit is profound, fails to improve, or worsens despite initial treatment, and additional hemodynamic treatment is necessary, then a pulmonary artery catheter is indicated (cate- gory B recommendation). In order to maximize cerebral blood flow, a pulmonary capillary wedge pressure in the range of 14 to $16 \mathrm{~mm} \mathrm{Hg}$ should be sought, ${ }^{91}$ as is a systolic blood pressure of 180 to $200 \mathrm{~mm} \mathrm{Hg}$ using various combinations of dopamine, dobutamine, norepinephrine and occasionally phenylephrine. When triple-H therapy is instituted, and especially when a pulmonary artery catheter has been inserted, very close patient monitoring is required to avoid complications such as pulmonary edema, heart failure and infarction, pulmonary artery rupture, pneumothorax, and catheter-related sepsis. ${ }^{92,93}$

If these hemodynamic parameters are not easily met, or if they do not result in reversal of the ischemic neurological deficit within approximately 30 minutes, it is recommended to proceed directly to endovascular treatment, providing this therapy is available at the treating institution (category $\mathrm{A}$ recommendation, level II-3 evidence). This treatment consists of cerebral transluminal balloon angioplasty, sometimes combined with intraarterial papaverine infusions. ${ }^{94-97}$ Intra-arterial therapy is also preferred over extreme hypertensive therapy in any patient possessing additional unruptured and unclipped aneurysms. Transluminal balloon angioplasty is successful in improving ischemic deficits in about three-quarters of patients. ${ }^{94-97}$ This treatment is not recommended for patients whose ruptured aneurysms have not been repaired (due to the risk of aneurysm rebleeding), and those with infarction evident on CT scan (due to the risk of hemorrhage into the new infarct).

\section{Summary statement: treatment of vasospasm}

To date, there is no treatment which has been proven in controlled trials to improve outcome following SAH through a prevention or reversal of vasospastic arterial narrowing alone (Table 6), although case-series would suggest that both triple- $\mathrm{H}$ therapy and balloon angioplasty are capable of reversing ischemia and preventing infarction in individual case situations. More recent large aneurysm series demonstrating a trend towards less vasospasm-related morbidity and mortality compared to historical controls provides anecdotal evidence that these modern therapies are having a favourable impact on overall outcome. ${ }^{26,98-101}$

Table 6:

\begin{tabular}{llll}
\hline Quality of evidence supporting various therapies for cerebral vasospasm \\
\hline Treatment & $\begin{array}{l}\text { Prevents/reverses } \\
\text { angiographic } \\
\text { vasospasm }\end{array}$ & $\begin{array}{l}\text { Prevents/reverses } \\
\text { clinical vasospasm }\end{array}$ & $\begin{array}{l}\text { Improves } \\
\text { Overall } \\
\text { Outcome }\end{array}$ \\
\hline $\begin{array}{l}\text { cisternal fibrinolysis grade I } \\
\text { (rt-PA) }\end{array}$ & no evidence & no evidence \\
$\begin{array}{l}\text { "Triple-H" therapy } \\
\text { (see text) }\end{array}$ & no evidence & grade III & no evidence \\
$\begin{array}{l}\text { Transluminal balloon grade II } \\
\text { angioplasty }\end{array}$ & grade III & no evidence \\
\hline
\end{tabular}

\section{Intraventricular hemorrhage and hydrocephalus:}

In general, it is recommended that any ventricular drain inserted before or at the time of surgery be left postoperatively as long as drainage is required to maintain normal ICPs. Acute hydrocephalus is seen in $15-30 \%$ of patients. ${ }^{102-108}$ If external drainage is required beyond 7 to 10 days, then either replacing 
the catheter with a ventriculoperitoneal shunt or another external catheter on the opposite side is recommended because of the potential risk of infection ${ }^{109}$ (category $\mathrm{B}$, level III evidence).

There is uncontrolled evidence that severe intraventricular hemorrhage causing persistent ventricular enlargement and contributing to elevated ICPs in the postoperative phase can be rapidly lysed with small doses of fibrinolytic agent rt-PA administered through the ventricular catheter ${ }^{110-112}$ (level III evidence). This treatment consists of $4 \mathrm{mg}$ of rt-PA administered directly into the lateral ventricles is followed by alternate-hourly or continuous CSF drainage against low resistance (approximately 2 $\mathrm{cm}$ pressure). CT scans and rt-PA injections are repeated daily until the CSF pathways are opened, which generally occurs within one to three days. In addition to facilitating ICP management, intraventricular fibrinolytic treatment maintains ventricular catheter patency, a benefit, but the efficacy of this treatment in improving patient outcome has not been tested in a randomized trial.

\section{Other postSAH complications:}

Cardiac, pulmonary and infectious complications frequently occur in patients recovering from SAH. Serum sodium imbalance is relatively common, and most often takes the form of mild to moderate hyponatremia. Hyponatremia following aneurysmal SAH is usually due to a salt-wasting syndrome rather than the syndrome of inappropriate antidiuretic hormone secretion (SIADH). ${ }^{113-115}$ Whereas fluid restriction is the treatment for SIADH, this is inappropriate for salt wasting, since hypovolemia can aggravate vasospastic cerebral ischemia. If the hyponatremia is mild, it should be simply followed, and isotonic fluid administration continued. However, if the serum sodium falls $<125 \mathrm{mEq} / \mathrm{L}$ and becomes symptomatic, it is recommended that hypertonic saline solutions (i.e., 3,5 , or $7 \%$ ) be administered to maintain normovolemia.

Diabetes insipidus can also occur following SAH and aneurysm surgery, and is recognized by high urine output $(>300$ $\mathrm{ml} /$ hour) prior to actual hypernatremia. Fluid balance is carefully followed and the diuresis, if severe or maintained, should be controlled with subcutaneous DDAVP injections.

\section{REFERENCES}

1. Phillips LHD, Whisnant JP, O'Fallon WM, Sundt TM Jr. The unchanging pattern of subarachnoid hemorrhage in a community. Neurology 1980; 30(10): 1034-1040.

2. Bonita R, Thomson S. Subarachnoid hemorrhage: epidemiology, diagnosis, management, and outcome. Stroke 1985; 16(4): 591594.

3. Sundt TM Jr, Whisnant JP. Subarachnoid hemorrhage from intracranial aneurysms. Surgical management and natural history of disease. N Engl J Med 1978; 299(3): 116-122.

4. Canadian Task Force on the Periodic Health Examination: The periodic health examination: 2. 1987 update. Can Med Assoc J 1988; 138: 618-626.

5. Mayberg MR, Batjer HH, Dace R, et al. Guidelines for the management of aneurysmal subarachnoid hemorrhage. A statement for healthcare professionals from a special writing group of the stroke council, American Heart Association. Stroke 1994; 25: 2315-2328.

6. Mayberg MR, Batjer HH, Dacey R, et al. Guidelines for the management of aneurysmal subarachnoid hemorrhage. A statement for healthcare professionals from a special writing group of the Stroke Council, American Heart Association. Circ. 1994; 90(5): 2592-2605.
7. Botterell EH, Lougheed WM, Scott JW, Vandewater SL. Hypothermia and interruption of carotid and vertebral circulation in the surgical management of intracranial aneurysms. J Neurosurg 1956; 13: 1-42.

8. Lougheed WM, Marshall, BM. Management of aneurysms of the anterior circulation by intracranial procedures. In: Youmans JR, ed. Neurological Surgery, Philadelphia: W.B. Saunders, 1973; 2: 731-767.

9. Hunt WE, Hess, RM. Surgical risk as related to time of intervention in the repair of intracranial aneurysms. J Neurosurg 1968; 28: $14-20$.

10. Drake CG. Report of World Federation of Neurological Surgeons committee on a universal subarachnoid hemorrhage grading scale (Neurosurgical forum). J Neurosurg: 1988; 68: 985-986.

11. Bassi P, Bandera R, Loiero M, Tognoni G, Mangoni A. Warning signs in subarachnoid hemorrhage: a cooperative study. Acta Neurol Scand 1991; 84(4): 277-281.

12. Leblanc $\mathbf{R}$, Winfield $\mathbf{J A}$. The warning leak in subarachnoid hemorrhage and the importance of its early diagnosis. Can Med Assoc J 1984; 131(10): 1235-1236.

13. Duffy GP. The "warning leak" in spontaneous subarachnoid haemorrhage. Med J Aust 1983; 1(11): 514-516.

14. Vermeulen M, van Gijn J. The diagnosis of subarachnoid haemorrhage. J Neurol Neurosurg Psychiatry 1990; 53(5): 365-372.

15. Adams HP Jr, Kassell NF, Torner JC, Sahs AL. CT and clinical correlations in recent aneurysmal subarachnoid hemorrhage: a preliminary report of the Cooperative Aneurysm Study. Neurology 1983; 33(8): 981-988.

16. van Gijn J, van Dongen KJ. The time course of aneurysmal haemorrhage on computed tomograms. Neuroradiology 1982; 23(3) 153-156.

17. Kassell NF, Kongable GL, Torner JC, Adams HP, Jr., Mazuz H. Delay in referral of patients with ruptured aneurysms to neurosurgical attention. Stroke $1985 ; 16(4)$ : 587-590.

18. Weir B, Myles T, Kahn M, et al. Management of acute subdural hematomas from aneurysmal rupture. Can J Neurol Sci 1984; 11: 371-376.

19. Duffy GP. Lumbar puncture in spontaneous subarachnoid haemorrhage. Br Med J - Clinical Research Ed 1982; 285(6349): 11631164.

20. Soderstrom CE. Diagnostic significance of CSF spectrophotometry and computer tomography in cerebrovascular disease. A comparative study in 231 cases. Stroke 1977; 5: 606-612.

21. Alberico RA, Patel M, Casey S, et al. Evaluation of the Circle of Willis with three-dimensional CT angiography in patients with suspected intracranial aneurysms. Am J Neuroradiol 1995; 16: 1571-1578.

22. Dorsch NWC, Young N, Kingston RJ, Compton JS. Early experience with spiral $\mathrm{CT}$ in the diagnosis of intracranial aneurysms. Neurosurgery $1995 ; 36$ : 230-238.

23. Hsiang JNK, Liang EY, Lam JMK, Zhu X, Poon WS. The role of computed tomography angiography in the diagnosis of intracranial aneurysms and emergent aneurysm clipping. Neurosurgery 1996; 38(3): 481-487.

24. Kassell NF, Torner JC. Aneurysmal rebleeding: a preliminary report from the Cooperative Aneurysm Study. Neurosurgery $1983 ; 13(5): 479-481$.

25. Fujii Y, Shigekazu, T, Sasaki O, et al. Ultra-early rebleeding in spontaneous subarachnoid hemorrhage. J Neurosurg 1996; 84 $35-42$.

26. Bailes JE, Spetzler RF, Hadley MN, Baldwin HZ. Management morbidity and mortality of poor-grade aneurysm patients. J Neurosurg 1990; 72: 559-566.

27. Le Roux PD, Elliott JP, Newell DW, Grady MS, Winn HR. Predicting outcome in poor-grade patients with subarachnoid hemorrhage: a retrospective review of 159 aggressively managed cases. J Neurosurg 1996; 85: 39-49.

28. Le Roux PD, Dailey AT, Newell DW, Grady MS, Winn, HR. Emergent aneurysm clipping without angiography in the moribund patient with intracerebral hemorrhage: the use of infusion computed tomography scans. Neurosurgery $1993 ; 33: 189-197$.

29. Kassell NF, Drake CG. Timing of aneurysm surgery. Neurosurgery 1982; 10: 514-519. 
30. O'Neill P, West CR, Chadwick DW, et al. Recurrent aneurysmal subarachnoid haemorrhage: incidence, timing and effects. A reappraisal in a surgical series. Br J Neurosurg 1988; 2(1): 43-48.

31. Mizukami M, Kawase T, Usami T, Tazawa T. Prevention of vasospasm by early operation with removal of subarachnoid blood. Neurosurgery 1982; 10(3): 301-307.

32. Taneda $\mathbf{M}$. The significance of early operation in the management of ruptured intracranial aneurysms-an analysis of 251 cases hospitalized within 24 hours after subarachnoid haemorrhage. Acta Neurochir 1982; 63(1-4): 201-208.

33. Le Roux PD, Elliott JP, Newell DW, et al. The incidence of surgical complications is similar in good and poor grade patients undergoing repair of unruptured anterior circulation aneurysms: a retrospective review of 355 patients. Neurosurgery 1996; 38: 887-895.

34. Kassell NF, Torner JC, Jane JA, Haley ECJ, Adams HP. The international cooperative study on the timing of aneurysm surgery I: overall management results. J Neurosurg 1990; 73: 18-36.

35. Kassell NF, Torner JC, Jane JA, Haley ECJ, Adams HP. The international cooperative study on the timing of aneurysm surgery II: surgical results. J Neurosurg 1990; 73: 37-47.

36. Haley ECJ, Kassell NF, Torner JC, and the participants. The international cooperative study on the timing of aneurysm surgery. The North American experience. Stroke 1992; 23: 205-214.

37. Ohman J, Heiskanen O. Timing of operation for ruptured supratentorial aneurysms: a prospective study. J Neurosurg 1989; 70: 5560 .

38. Heiskanen O, Poranen A, Kuurne T, Valtonen S, Kaste M. Acute surgery for intracerebral haematomas caused by rupture of an intracranial arterial aneurysm. A prospective randomized study. Acta Neurochir 1988; 90(3-4): 81-83.

39. Batjer HH, Samson DS. Emergent aneurysm surgery without cerebral angiography for the comatose patient [see comments]. Neurosurgery 1991; 28(2): 283-287.

40. Guglielmi G, Vinuela F, Sepetka I, Macellari V. Electrothrombosis of saccular aneurysms via endovascular approach, Part 1. Electrochemical basis, technique, and experimental results. J Neurosurg 1991; 75: 1-7.

41. Guglielmi G, Vinuela F, Dion J, Duckwiler G. Electrothrombosis of saccular aneurysms via endovascular approach, Part 2. Preliminary clinical experience. J Neurosurg 1991; 75: 8-14.

42. Guglielmi G, Vinuela F, Duckwiler G, et al. Endovascular treatment of posterior circulation aneurysms by electrothrombosis using electrically detached coils. J Neurosurg 1992; 77: 515-524.

43. Halbach V, Higashida R, Dowd C, et al. The efficacy of endosaccular aneurysm occlusion in alleviating neurological deficits produced by mass effect. J Neurosurg 1994; 80: 659-666.

44. Mawad M, Mawad J, Cartwright J, Gokaslan Z. Long-term histopathologic changes in canine aneurysms embolized with Guglielmi detachable coils. Am J Neuroradiol 1995; 16: 7-13.

45. Nichols D. Endovascular treatment of the acutely ruptured intracranial aneurysm. J Neurosurg 1995; 79: 1-2.

46. Zubillaga A, Guglielmi G, Vinuela F, Duckwiler G. Endovascular occlusion of intracranial aneurysms with electrically detachable coils. Am J Neuroradiol 1994; 15: 815-820.

47. Casasco A, Aymard A, Gobin P, et al. Selective endovascular treatment of 71 intracranial aneurysms with platinum coils. J Neurosurg 1993; 79: 3-10.

48. Graves VB, Strother CM, Duff TA, Perl J. II. Early treatment of ruptured aneurysms with Guglielmi detachable coils: effect on subsequent bleeding. Neurosurgery 1995; 37: 640-648.

49. Gobin YP, Vinuela $\mathrm{F}$, Gurian $\mathrm{JH}$, et al. Treatment of large and giant fusiform intracranial aneurysms with Guglielmi detachable coils. J Neurosurg 1996; 84: 55-62.

50. McDougall CG, Halbach VV, Dowd CF, et al. Endovascular treatment of basilar tip aneurysms using electrolytically detachable coils. J Neurosurg 1996; 84: 393-399.

51. Zubillaga AF, Guglielmi G, Vinuela F, et al: Endovascular occlusion of intracranial aneurysms with electrically detachable coils: correlation of aneurysm neck size and treatment results. Am J Neuroradiol 1994; 15: 815-820.
52. Guglielmi G, Vinuela F, Duckwiler G, et al. Endovascular treatment of posterior circulation aneurysms by electrothrombosis using electrically detachable coils. J Neurosurg 1992; 77: 515524.

53. Pierot L, Boulin A, Castaings L, Rey A, Moret J. Selective occlusion of basilar artery aneurysms using controlled detachable coils: report of 35 cases. Neurosurgery 1996; 38(5): 948-954.

54. Civit T, Auque J, Marchal JC, et al. Aneurysm clipping after endovascular treatment with coils: a report of eight patients. Neurosurgery $1996 ; 38(5)$ : 955-961.

55. Lawton MT, Hamilton MG, Morcos JJ, Spetzler RF Revascularization and aneurysm surgery: current techniques, indications, and outcome. Neurosurgery 1996; 38: 83-94.

56. Winn HR, Richardson AE, Jane JA. Late morbidity and mortality of common carotid ligation for posterior communicating aneurysm: a comparison to conservative treatment. J Neurosurg 1977; 47: 727-736.

57. Jha AN, Butler P, Lye RH, Fawcitt RA. Carotid ligation: what happens in the long term? J Neurol Neurosurg Psychiatry 1986; 49(8): 893-898.

58. Fox AJ, Vinuela F, Pelz DM, et al. Use of detachable balloons for proximal artery occlusion in the treatment of unclippable cerebral aneurysms. J Neurosurg 1987; 66: 40-46.

59. Todd NV. Aneurysm rebleeding after treatments that leave the aneurysm sac patent. Br J Neurosurg 1990; 4(5): 373-379.

60. Minakawa T, Koike T, Fujii Y, et al. Long term results of ruptured aneurysms treated by coating. Neurosurgery 1987; 21(5): 660-663.

61. Qureshi AI, Frankel MR. Recognition and management of subarachnoid hemorrhage. Heart Disease \& Stroke 1994; 3(5): 270274.

62. Solomon RA, Fink ME, Lennihan L. Early aneurysm surgery and prophylactic hypervolemic hypertensive therapy for the treatment of aneurysmal subarachnoid hemorrhage. Neurosurgery 1988; 23(6): 699-704.

63. Solomon RA, Post KD, McMurtry JGD. Depression of circulating blood volume in patients after subarachnoid hemorrhage: implications for the management of symptomatic vasospasm. Neurosurgery $1984 ; 15(3): 354-361$.

64. Hart RG, Byer JA, Slaughter JR, Hewett JE, Easton JD. Occurrence and implications of seizures in subarachnoid hemorrhage due to ruptured intracranial aneurysms. Neurosurgery $1981 ; 8(4)$ : 417-421.

65. Ukkola V, Heikkinen ER. Epilepsy after operative treatment of ruptured cerebral aneurysms. Acta Neurochir 1990; 106(3-4): 115-118.

66. Ohman J. Hypertension as a risk factor for epilepsy after aneurysmal subarachnoid hemorrhage and surgery. Neurosurgery 1990 27(4): 578-581.

67. Hasan D, Schonck RS, Avezaat CJ, et al. Epileptic seizures after subarachnoid hemorrhage. Ann Neurol 1993; 33(3): 286-291.

68. Keranen T, Tapaninaho A, Hernesniemi J, et al. Late epilepsy after aneurysm operations. Neurosurgery 1985; 17: 897-900.

69. Sundaram MB, Chow F. Seizures associated with spontaneous subarachnoid hemorrhage. Can J Neurol Sci 1986; 13(3): 229-231.

70. Pickard JD, Murray GD, Illingworth R, et al. Effect of oral nimodipine on cerebral infarction and outcome after subarachnoid haemorrhage: British aneurysm nimodipine trial. Br Med J 1989; 298(6674): 636-642.

71. Ohman J, Servo A, Heiskanen O. Long-term effects of nimodipine on cerebral infarcts and outcome after aneurysmal subarachnoid hemorrhage and surgery. J Neurosurg 1991; 74(1): 8-13.

72. Allen GS, Ahn HS, Preziosi TJ, et al. Cerebral arterial spasm-a controlled trial of nimodipine in patients with subarachnoid hemorrhage. N Engl J Med 1983; 308(11): 619-624.

73. Mee E, Dorrance D, Lowe D, Neil-Dwyer G. Controlled study of nimodipine in aneurysm patients treated early after subarachnoid hemorrhage. Neurosurgery 1988; 22(3): 484-491.

74. Petruk KC, West M, Mohr G, et al. Nimodipine treatment in poorgrade aneurysm patients: results of a multicenter double-blind placebo-controlled trial. J Neurosurg 1988; 68: 505-517.

75. Philippon J, Grob R, Dagreou F, et al. Prevention of vasospasm in subarachnoid haemorrhage. A controlled study with nimodipine. Acta Neurochir 1986; 82(3-4): 110-114. 
76. Robinson MJ, Teasdale GM. Calcium antagonists in the management of subarachnoid haemorrhage. Cerebrovasc Brain Met Rev 1990; 2(3): 205-226.

77. Barker FG, Ogilvy CS. Efficacy of prophylactic nimodipine for delayed ischemic deficit after subarachnoid hemorrhage: a metaanalysis. J Neurosurg 1996; 84: 405-414.

78. Findlay JM, Macdonald RL, Weir BK. Current concepts of pathophysiology and management of cerebral vasospasm following aneurysmal subarachnoid hemorrhage. Cerebrovasc Brain Met Rev 1991; 3(4): 336-361.

79. Findlay JM, Kassell NF, Weir BKA, et al. A randomized trial of intraoperative, intracisternal tissue plasminogen activator for the prevention of vasospasm. Neurosurgery 1995; 37: 168-178.

80. Findlay JM, Weir BK, Kassell NF, Disney LB, Grace MG. Intracisternal recombinant tissue plasminogen activator after aneurysmal subarachnoid hemorrhage. J Neurosurg 1991; 75(2): 181-188.

81. Hutchison K, Weir B. Transcranial Doppler studies in aneurysm patients. Can J Neurol Sci 1989; 16(4): 411-416.

82. Romner B, Ljunggren B, Brandt L, Saveland H. Correlation of Iranscranial Doppler sonography findings with timing of aneurysm surgery. J Neurosurg 1990; 73(1): 72-76.

83. Sekhar LN, Wechsler LR, Yonas H, Luyckx K, Obrist W. Value of transcranial Doppler examination in the diagnosis of cerebral vasospasm after subarachnoid hemorrhage. Neurosurgery 1988; 22(5): 813-821.

84. Miller JD, Smith RR. Transcranial Doppler sonography in aneurysmal subarachnoid hemorrhage. Cerebrovasc Brain Met Rev 1994; 6(1): 31-46.

85. Trumble ER, Muizelaar JP, Myseros JS, Choi SC, Warren BB. Coagulopathy with the use of hetastarch in the treatment of vasospasm. J Neurosurg 1995; 82: 44-47.

86. Awad IA, Carter LP, Spetzler RF, Medina M, Williams FC Jr. Clinical vasospasm after subarachnoid hemorrhage: response to hypervolemic hemodilution and arterial hypertension. Stroke 1987; 18(2): 365-372.

87. Kassell NF, Peerless SJ, Durward QJ, et al. Treatment of ischemic deficits from vasospasm with intravascular volume expansion and induced arterial hypertension. Neurosurgery 1982; 11(3): 337-343.

88. Origitano TC, Wascher TM, Reichman OH, Anderson DE. Sustained increased cerebral blood flow with prophylactic hypertensive hypervolemic hemodilution ("triple-H" therapy) after subarachnoid hemorrhage. Neurosurgery 1990; 27(5): 729-739; discussion 739-740.

89. Archer DP, Shaw DA, Leblanc RL, Tranmer BI. Haemodynamic considerations in the management of patients with subarachnoid haemorrhage. Can J Anaes 1991; 38: 454-470.

90. Hino A, Ueda S, Mizukawa N, Imahori Y, Hiroshi T. Effect of hemodilution on cerebral hemodynamics and oxygen metabolism. Stroke 1992; 23: 423-426.

91. Levy ML, Day JD, Zelman V, Giannotta SL. Cardiac performance enhancement and hypervolemic therapy. Neurosurg Clin N Am 1994; 5(4): 725-739.

92. Rosenwasser RH, Jallo JI, Getch CC, Liebman, KE. Complications of Swan-Ganz catheterization for hemodynamic monitoring in patients with subarachnoid hemorrhage. Neurosurgery $1995 ; 37: 872-876$.

93. Miller JA, Dacey RG Jr, Diringer MN. Safety of hypertensive hypervolemic therapy with phenylephrine in the treatment of delayed ischemic deficits after subarachnoid hemorrhage. Stroke 1995; 26: 2260-2266.

94. Barnwell SL, Higashida RT, Halbach VV, et al.Transluminal angioplasty of intracerebral vessels for cerebral arterial spasm: reversal of neurological deficits after delayed treatment. Neurosurgery $1989 ; 25(3)$ : 424-429.

95. Coyne TJ, Montanera WJ, Macdonald RL, Wallace MC. Percutaneous transluminal angioplasty for cerebral vasospasm after subarachnoid hemorrhage. Can J Surg 1994; 37(5): 391-396.
96. Zubkov YN. Treatment of patients with intracranial arterial aneurysms in the haemorrhagic period. Neurol Res 1994; 16(1): 6-8.

97. Livingston K, Guterman LR, Hopkins LN. Intraarterial papaverine as an adjunct to transluminal angioplasty for vasospasm induced by subarachnoid hemorrhage [published erratum appears in Am J Neuroradiol 1993 Jul-Aug; 14(4): 1025]. Am J Neuroradiol 1993; 14(2): 346-347.

98. Saveland H, Hillman J, Brandt L, et al. Overall outcome in aneurysmal subarachnoid hemorrhage. A prospective study from neurosurgical units in Sweden during a 1-year period. J Neurosurg 1992; 76(5): 729-734.

99. Saveland $\mathrm{H}$, Brandt $\mathrm{L}$. Which are the major determinants for outcome in aneurysmal subarachnoid hemorrhage? A prospective total management study from a strictly unselected series. Acta Neurol Scand 1994; 90(4): 245-250.

100. Proust F, Hannequin D, Langlois O, Freger, P, Creissard P. Causes of morbidity and mortality after ruptured aneurysm surgery in a series of 230 patients. The importance of control angiography. Stroke 1995; 26: 1553-1557.

101. Le Roux PD, Elliott J, Downey L, et al. Improved outcome after rupture of anterior circulation aneurysms: a retrospective 10-year review of 224 good-grade patients. J Neurosurg 1995; 83: 394 402.

102. Hasan D, Tanghe HL. Distribution of cisternal blood in patients with acute hydrocephalus after subarachnoid hemorrhage. Ann Neurol 1992; 31(4): 374-378

103. Graff-Radford NR, Torner J, Adams H Jr, Kassell NF. Factors associated with hydrocephalus after subarachnoid hemorrhage. A report of the Cooperative Aneurysm Study. Arch Neurol 1989; 46(7): 744-752.

104. Galera R, Greitz T. Hydrocephalus in the adult secondary to the rupture of intracranial arterial aneurysms. J Neurosurg 1970; 32(6): 634-641.

105. Raimondi $\mathrm{AJ}$, Torres $\mathrm{H}$. Acute hydrocephalus as a complication of subarachnoid hemorrhage. Surg Neurol 1973; 1(1): 23-26.

106. van Gijn J, Hijdra A, Wijdicks EF, Vermeulen M, van Crevel $H$. Acute hydrocephalus after aneurysmal subarachnoid hemorrhage. J Neurosurg 1985; 63(3): 355-362.

107. Vassilouthis J, Richardson AE. Ventricular dilatation and communicating hydrocephalus following spontaneous subarachnoid hemorrhage. J Neurosurg 1979; 51(3): 341-351

108. Mehta V, Holness RO, Connolly S, Walling S, Hall R. Acute hydrocephalus following aneurysmal subarachnoid hemorrhage. Can J Neurol Sci 1996; 23: 40-45.

109. Mayhall CG, Archer NH, Lamb VA, et al. Ventriculoscopy-related infections. A prospective epidemiologic study. $\mathrm{N}$ Engl J Med 1984; 310: 553-559.

110. Rhode V, Schaller C, Hassler HE. Intraventricular recombinant tissue plasminogen activator for lysis of intraventricular hemorrhage. J Neurol Neurosurg Psychiatry 1995; 58: 447-451.

111. Mayfrank L, Lippitz B, Groth M, Bertalanffy H, Bilsbach JM. Effect of recombinant tissue plasminogen activator on clot lysis and ventricular dilatation in the treatment of severe intraventricular hemorrhage. Acta Neurochir 1993; 122: 32-38.

112. Findlay JM, Grace MGA, Weir BKA. Treatment of intraventricular hemorrhage with tissue plasminogen activator. Neurosurgery 1993; 32: 941-947.

113. Wijdicks EF, Vermeulen M, Hijdra A, van Gijn J. Hyponatremia and cerebral infarction in patients with ruptured intracranial aneurysms: is fluid restriction harmful? Ann Neurol 1985; 17(2): 137-140.

114. Diringer M, Ladenson PW, Stern BJ, Schleimer J, Hanley DF. Plasma atrial natriuretic factor and subarachnoid hemorrhage. Stroke 1988; 19(9): 1119-1124.

115. Harrigan MR. Cerebral salt wasting syndrome: a review. Neurosurgery $1996 ; 38: 152-160$. 